\title{
SÍMBOLOS Y PALABRAS EN EL SETENARIO DE ALFONSO X
}

El Setenario alfonsí, cuyo texto fue dado a conocer por Kenneth $H$. Vanderford ${ }^{1}$ con estudio preliminar traducido por Raimundo Lida $^{2}$, desconcierta a quien por primera vez se acerca a sus páginas. Todo contribuye a producir extrañeza. La falta de los primeros folios, una importante laguna al final de la ley XI y el haber quedado, al parecer, inacabado hacen que sea difícil reconocerle un plan. Hay aparente desconexión entre las partes conservadas: los prolegómenos se ocupan de los nombres de Dios, incluyen un panegírico de Fernando III y terminan con una alabanza de Sevilla; entrando ya en materia, encontramos consideraciones sobre el entendimiento y la naturaleza, las edades del hombre, la sabiduría y las artes liberales, los metales y su elaboración, las diversas formas de religiosidad, el paganismo y la fe verdadera, los artículos del Credo y finalmente, con mayor extensión, los sacramentos. Temas tan varios se tratan distribuyendo la exposición según un módulo septenario que, mantenido implacablemente, llega a hacerse obsesivo. El lector se siente perdido en una maraña de similitudes que en muchos casos están consagradas por la tradición eclesiástica, pero con frecuencia son insólitas y parecen, al menos en el primer momento, caprichosas o descabelladas. El jurista califica de farragosa la sucesión de capítulos que se llaman leyes sin que en ellos se legisle. El filólogo que se haya asomado alguna vez a las Etimologias isidorianas no se sorprenderá ante las filiaciones y exégesis que se dan en el Setenario a multitud de palabras; pero sufrirá la tentación de juzgarlas precientíficas y pueriles.

A pesar de todo ello, esta obra temprana de la producción alfonsí ofrece singular interés: destaca por su carácter personal, como tributo del rey a la memoria de su padre don Fernando y como

1 Instituto de Filología, Buenos Aires, 1945.

2 "Bibliografía de Raimundo Lida", NRFH, 24 (1975), ix (con referencia a la versión publicada como artículo en la $R F H, 3$ (1941), 233-262. 
ejecución de un mandato de él recibido; anticipa propósitos, leyes y pasajes de las Partidas, especialmente de la Primera; sus definiciones y equivalencias léxicas manifiestan ya la constante preocupación de don Alfonso por el origen y contenido de las palabras; y la agrupación de éstas apunta a alguna cuestión que sólo la semántica estructural de nuestros días ha planteado a fondo. Además, el problema semántico-interpretativo se enmarca en otro más amplio, referente a la significación trascendental del universo, con lo que se ofrece un panorama de la cosmovisión que había de presidir la obra entera del monarca. El presente artículo sólo versará sobre algunos aspectos poco estudiados por Vanderford o ajenos a su atención.

\section{ORganización EXPositiva dEL "SETENARIo"}

Formalmente, lo primero que salta a la vista en el Setenario es la aplicación sistemática de ciertos procedimientos expositivos. En primer lugar, la disposición septenaria que da nombre al libro; Vanderford hizo hincapié en ella y la relacionó acertadamente con el valor especial conferido al número siete en uno de los prólogos de las Partidas ${ }^{3}$. En segundo término, otros esquemas complementarios que afianzan la unidad estilística de la obra; veámoslos: a continuación de cada serie enumerativa o de cada división, los siete términos que las constituyen son objeto de sendas glosas portadoras de explicaciones o de argumentos probatorios; si se nos dice que la letra A "muestra [...] ssiete nombres de Dios en latín, que sson estos: A u rora, Artif ex, A r ra, A uxilium, Agnus, Angelus, Alta re" ${ }^{4}$, se añade inmediatamente:

Onde el nonbre de Aurora, que quiere dezir 5 la lunbre que viene quando aluoreçe ante que ssalga el ssol, esto sse entiende que él alumbra el mundo, assí commo el ssol ffaz el alua, con la ssu merçet et escalienta el ssol con la ssu piedat. Artiffex quiere dezir maestro conplido, e esto con grant rrazón; ca él ffizo las cosas e las ssopo ffazer de tal manera que por otro maestro non pueden sser asmadas nin ffechas. Aura quiere otrossí dezir oriella. Esto sse entiende por Dios; ca él es oriella buena e tenprada e ssana con que guaresçen las enffermedades e rressuçitan los muertos e sse

3 Introducción a la ed. cit., pp. xxviii-xxxi. Como dice Vanderford, ese prólogo de la Primera Partida tiene que proceder del Setenario, cuyos manuscritos conservados carecen de los folios iniciales y de los correspondientes al final de la ley XI.

4 Cada nombre figura en el manuscrito dentro de un óvalo, que la ed. de Vanderford sustituye con un recuadro.

5 En el ms. T, "que quiere dezir por la lunbre", "esto sse entiende que". 
perdonan los peccados. Auxilium es tanto commo ayuda e defendedor de todas las cosas que con él sse tienen...6

Y así sucesivamente. Si en este y otros lugares la interpretación parece al autor lo bastante sólida para no requerir pruebas, en muchas ocasiones va respaldada por la autoridad de testimonios bíblicos, citados de ordinario textualmente. No es preciso que las glosas tengan igual extensión: junto a las simples y breves hay otras complejas, divididas en miembros que primero se enumeran y después motivan nuevas explicaciones, nuevos paralelos interpretativos y nuevos testimonios corroboradores. Ejemplos de ambos tipos se dan en la ley XLIII, "De cómo los que aorauan la tierra, a Santa María querían aorar ssi bien lo entendiessen" ?:

Doze ffueron los apóstolos, segunt que de ssuso oyestes, de qui rrecibiestes la mandadería de Ihesu Cristo en cómmo auemos a creer e a obrar. Et por esta mandadería entendemos que las crençias que los otros creyen, de que ffablamos en las leyes ante désta, non eran çiertas, porque las non entendien los omnes así commo deuyen. Mas eran a ssemeiança desta ssanta ley que Dios auye a dar en el mundo. Ca los que aorauan a la tierra queríen tanto mostrar commo que orassen a Ssanta María; ca ella ouo en sí siete cosas a ssemeiança de la tierra.

La situación y sentido de esta "ley", expresos en sus primeras líneas, merecen comentario. Tras el lema, el texto comienza con una referencia de enlace con el capítulo precedente, la ley XLII, "De las palabras que dixieron los apóstolos en cómmo creyen", esto es, lo que cada uno aportó a la composición del Credo, fórmula definitiva de la $\mathrm{Fe}$ cristiana. A continuación se enuncia una de las ideas capitales del Setenario: el paganismo idólatra era falso, pero vislumbraba de manera inconsciente algo de la creencia verdadera. Antes (leyes XIX-XXXV) se han descrito las distintas "antoianças e setas e opiniones" de los gentiles y se ha resumido (leyes XXXVI-XLII) la doctrina evangélica; ahora se va a puntualizar cómo cada forma de idolatría anunciaba sin saberlo ciertos aspectos del Cristianismo. La serie de paralelos, como la anterior de errores, comienza por la adoración a la tierra, el más pesado e inerte de los cuatro elementos; sigue con la deificación del agua, el aire y el fuego, cada cual más leve y activo que los que le anteceden; y culmina con el culto a hombres vivos y muertos, convertidos en dioses-planetas, y en el tributado a las constelaciones del ochavo cielo. El capítulo que nos ocupa se

6 Setenario, ed. cit., pp. 3-4.

7 Ibid., pp. 73-76. 
refiere, pues, al grado más primitivo de esta creciente elevación; sin embargo, los parangones que el Rey Sabio establece entre la tierra, "la más baxa cosa e la más vil que [Dios] ffiziera" ${ }^{8}$, y Santa María no han de entenderse como agravio para ésta, cuyo culto aparece prefigurado también por el que otros gentiles rindieron a la Luna (ley XLVIII) y al signo zodiacal de Virgo (ley LX) : según don Alfonso la devoción mariana se hallaba latente en todos los niveles del paganismo, desde su manifestación más rastrera hasta las que se alzaban a contemplar alturas estelares.

Contra lo usual en otros capítulos, las siete semejanzas tratadas en el XLIII no se ensartan en una enumeración inicial, quizá por la dificultad de condensar cada una en un solo vocablo o en un sintagma breve. Se omiten aquí por consabidos casi todos ${ }^{9}$ los términos que en cada paralelo se refieren a realidades naturales (bajeza, sequedad y fertilidad de la tierra; tiempos señalados para fructificar; sabrosía y provecho de los frutos) ; en cambio se explicitan los términos que corresponden a aquéllos en el orden espiritual (humildad de María; su hermosura ajena a toda mancha de pecado; oportunidad con que fructificó en Jesucristo; belleza, virtudes y beneficio de este supremo Fruto). Las tres primeras similitudes no llevan ordinal ${ }^{10}$ que las introduzca; enlazan directamente con el anuncio, hecho hacia el final del preámbulo, de "siete cosas" comunes a la tierra y a Santa María:

[1] Que ffué más baxa en sser homillosa que otra mugier, assí commo sse muestra por las palabras que dixo al Angel; que allí ol dixo que ssería bienauenturada entre todas las mugieres porque ssería madre del rrey del çielo e de la tierra, allí rrespondió ella que era ssu ssierua e que ffiziese della lo que quisiese ssegunt ssu uoluntad. [2] Et ffué sseca e enxuta de todo peccado, ssegunt dixo Ssalamón, que ffué rrey e propheta, por Spíritu Ssanto en boz de Dios: Toda eres fermosa, la mi amiga, e ninguna manziella non ha en ti. [3] Que obró en ella el Spíritu Ssanto e la labró por que diesse buen ffructo, ssegunt dixo el Ángel mismo: El Spíritu Ssanto verná en ti e la uertud de Dios te cobrirá. Et esto sse entiende por tres rrazones que ffazían en la tierra leuar buen ffructo: la vna, labrarla; la otra, estercolarla; la terçera, rregarla. Labrarla ffué apartamiento que ffizo el Spíritu Santo en el cuerpo della en que descendiese Ihesu Cristo para sser omne e Dios. Et el estercolamiento ffué la vida lazrada que ffizo en este mundo e la crúa muerte que ssuffrió por nos, en que ffué despreçiado e dese-

8 Ibid., p. $50_{26}$.

9 Sólo se mencionan expresamente las tareas materiales de la labranza, relacionadas con las maravillas de Dios en María, y el sabor del buen fruto, comparado con los salutíferos efectos de las palabras y obras de Cristo.

10 Lo suplo, entre corchetes, en la cita que sigue. 
chado, bien assí commo el estiércol que desecha omne de ssu casa, ssegunt dixo el propheta Dauid: Yo so gusano e non omne, denuesto de los omnes e desechamiento de las gentes. Ca bien commo el estiércol ffaze podreçer el grano de trigo, que ssi non podreciesse non leuaría ífructo, bien assí Nuestro Ssennor Ihesu Cristo non pudiera llegar áquella onrra que deuye ssi ante non passasse por aquel pudrimiento de todos los males e de las penas quel ffizieron, ssegunt él mismo dixo, que quanto el grano de trigo ssouyese en tierra e non sse dannasse, que non leuaría ffructo; mas a la ora que ffuese muerto, que sse entendíe por dannado, que leuarie mucho ffructo. La terçera, rregar, que non se podía ffazer ssin agua, muestra la virginidat de Ssanta María, que ouo ante que ffuese prennada e en sseyéndolo; e después que parió, ffincó más clara e más linpia que agua. Et con esta agua ffué rregada la lauor que ffizo el Spíritu Ssanto en ella, por que esta tierra leuó buen ffructo en el tiempo que conuyníe.

Las semejanzas [l] y [2] son muy concisas: se limitan a exaltar sendas excelencias de María probándolas con palabras de la Anunciación y del Cantar de los Cantares. No obstante, hay en la primera un germen de desarrollo sabio con las correspondencias antitéticas alli/alli, dixo/rrespondió, seria/era, bienauenturada/ssierua. La segunda, más escueta, cifra su elocuencia en la cita del versículo de Salomón, sin más que recordar su carácter profético y su inspiración divina. En marcado contraste con tal parquedad, el tercer parangón se extiende y ramifica profusamente: tras enunciar el término sobrenatural de la correspondencia ("Que obró en ella el Spíritu Ssanto e la labró por que diesse buen ffructo") y la autoridad evangélica de apoyo, la interpretación se organiza mediante la división tripartita labrar / estercolar / rregar, a la que siguen tres paralelos exegéticos: uno de ellos, el que relaciona el estercolamiento de la tierra con los padecimientos de Jesús, genera a su vez dos comparaciones, sustentadas con textos del Salmo XXI y del Evangelio de San Juan. Las cuatro semejanzas restantes llevan glosas de estructura binaria, breves en la cuarta y quinta, pero muy extensa en la sexta, cuya dicotomía ffizo e dixo se expande en las de en obralen palabra, sanar los enfermos/sanar los quebrantados de coraçón, con sus respectivas citas de la Escritura acompañadas de comentario:

La quarta, que dió buen ffructo en el tienpo que deuye. Et esto ffué quando nasçió Ihesu Cristo; que era perdido el mundo por desconnosçençia. Et esto sse proeua por dos rrazones: la vna, por los malos ffechos que y ffazíen; la otra, que los prophetas e otros santos omnes le pidien a Dios que abaxase los çielos e les enbiase su ffijo, que les auya a ssaluar. Et otros dizíen que por la ssu voluntad rronpería los çielos e uerníe. La quinta, que nos dió ffructo ffermoso; 
que ouo en ssí todas las ffermosuras que sser podíen: la primera, de Dios, que ssobra todas las cosas; la ssegunda, ffermosura de omne lo más que puede sser, ssegunt el propheta Dauid dixo: Ffermoso de fforma ssobre todos los ffijos de los omnes. La sesta, que nos dió ffructo ssabroso; ca assí commo el ffructo sabroso e bueno ssabe bien a los que an gusto conplido e çierto, assí lo que Nuestro Ssennor Ihesu Cristo ffizo e dixo ssopo bien a todos los omnes buenos e entendidos. Et este ssabor ffué en dos maneras: la vna, en obra; la otra, en palabra. En obra ffué quando ssanó los enffermos e los peccadores, ssegunt dizen los Enangelios, que la uertud ssalíe dél para ssanar los enffermos. Et Dauid el propheta otrosí dixo que ssana los quebrantados de coraçón, que sse entiende por los peccadores. $\mathrm{E}$ ata los ssus quebrantamientos, tolliéndoles los peccados, ssegunt él mismo dixo quadol preguntaron los judíos, que ninguno non podíe perdonar los pecados ssinon Dios solo. Et díxoles él que quál era mayor cosa, de perdonar los peccados o dezir al contrecho: Leuántate e anda. Et en esto les dió a entender que lo podría ffazer todo; que tan ligero le era lo vno commo lo ál. Et las palabras otrossí ffueron muy ffermosas e muy ssabrosas; que lo que él dixo non ffué ál ssinon mostrarnos cómmo ganásemos el rregno de los çielos e nos guardássemos de ffazer cosas por que ouyésemos de yr a las penas del inffierno. Et más, que nunca ffablaua ssinon dando buen conseio e buen castigo e buen ensienplo por que deuan los omnes dexar el mal e ffazer el bien. Et esto sse proeua por lo que dixo Dauid el propheta por Ihesu Cristo: Es esparzida la graçia de bien ffablar en los tus labios, e por esso te bendixo Dios para ssienpre.

Por último la setena se estructura también en disposición binaria mediante referencias al Pan y Vino eucarísticos y contrapesando miembros simétricos del discurso; la reiteración de elementos comunes (ssaqué/ssacó, que sse entiende por/que sse entiende por, alegra/alegria) pone de relieve la divergencia de los que se contraponen:

La vii, que nos dió grant pro; ca el pan ssanto que nós rreçebimos <que> es el ssu cuerpo, comiendo cadal día por ssacriffiçio, et el vino que beuemos es la ssu ssangre, que nos aprouecha de guisa que nos abonda en este mundo por que podamos bien beuir e ganar el otro que dura ssienpre, ssegunt dixo el propheta Dauid: Ssaque pan de la tierra -que sse entiende por el cuerpo de Nuestro Ssennor Ihesu Cristo, que ssacó de Ssanta María - et el vino alegra el coraçón de los omnes- que sse entiende por la ssangre de Ihesu Cristo, que nos dará alegría por ssienpre en parayso.

Pese a las diferencias de extensión y complejidad, el procedimiento expositivo no varía. La cohesión interna del discurso se refuerza con repeticiones de fórmulas introductoras: sse entiende 
por, quiere dezir, et esto sse proeua por, ssegunt dize o dixo, bien commo... bien assi, etc. Esta sólida contextura no es perceptible sólo en la ley XLIII, sino general en todo el Setenario, obra dispuesta como organismo, ejecutada con arreglo a un sistema y conformada en un estilo peculiar. A esta unidad formal corresponde una concepción unitaria del mundo. Intentemos adentrarnos en ella.

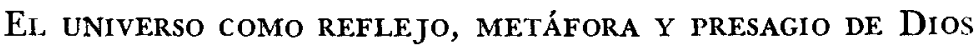

Todas las semejanzas, paralelos y prefiguraciones que se entretejen en el Setenario giran en torno a la idea axial de que el ser y el acaecer del universo entero son simbólicos. Por absurdo que a primera vista parezca, hacen pensar en los versos de Baudelaire:

La Nature est un temple où de vivants piliers

Laissent parfois sortir de confuses paroles;

L'homme y passe à travers des forêts de symboles

Qui l'observent avec des regards familiers...

Pero, a diferencia de Baudelaire, Alfonso el Sabio no indaga los símbolos de la naturaleza para encontrar sutiles o profundas correspondencias de sensaciones, sino para descubrir en la Creación ocultos reflejos del Creador. También para el rey de Castilla hay, como para el autor de Les fleurs du mal, faros que transmiten señales a lo largo de la historia de la humanidad; ahora bien, el poeta francés detecta, en el mensaje emitido por los genios de la pintura, un angustiado sollozo de protesta, "cet ardent sanglot qui roule d'âge en âge" y que -testimonio supremo de la dignidad humana- muere bordeando la eternidad divina; en cambio don Alfonso ve en los hombres y hechos del Antiguo Testamento y del paganismo el anhelo y premonición de la acción salvadora que Dios había de llevar a cabo.

El monarca seguía una tradición largamente consagrada. Jesús, refiriéndose a su propia muerte y resurrección recuerda el milagro de Jonás y se identifica con el Siervo de Yahvé cantado por Isaías. Los evangelistas señalan numerosos pasajes de la Escritura como anuncio de lo que actos o padecimientos de Cristo cumplieron: las persecuciones y tormentos de que son objeto el Justo de los Salmos o Jeremías se entendieron como profecías de los sufridos por el Salvador. La mentalidad cristiana creó una liturgia cuyo ritual y vestiduras tienen sentido simbólico, y empezó muy pronto a interpretar espiritualmente fenómenos de la naturaleza y del vivir diario. Según Prudencio, el canto del gallo significa la llamada de Cristo a los pecadores para que salgan de su letargo, la salida del 
sol representa la gracia divina que alumbra a las almas, y hasta los alimentos poseen valor simbólico. Ocho siglos después, alabando al Señor con todas sus creaturas, San Francisco de Asís afirmaba que "messor lo frate Sole [...] de Te, Altissimo, porta significatione". Con menos unción y más razonamientos la ley LI del Setenario habla "de cómmo errauan los que orauan el ssol, cuydando que la nobleza que él auye en ssí era de ssuyo, e non entendíen cómmo lo auya de Dios", pues Dios "es luz conplida que alumbra a todos, et esto en siete maneras: que es luz clara e rresplandeçiente que es ssotil, ayuntada, fermosa, temerosa, ssabrosa". Cada uno de los siete adjetivos se justifica a continuación con autoridades bíblicas $u$ otros argumentos ${ }^{11}$.

El mundo está, pues, concebido como un inmenso libro escrito en clave por su Hacedor. Hay que esforzarse por descifrarlo, por desentrañar su gran metáfora, preñada de metáforas parciales, cuyo sentido último ha de coincidir con la verdad revelada. Si, como hemos visto, las cualidades físicas de la tierra apuntan a las virtudes de Santa María y a las maravillas que el Señor obró en ella, las cualidades del agua predicen el bautismo; las del aire anuncian la limpia vida de Cristo, y las del fuego, la acción del Espíritu Santo ${ }^{12}$. Don Alfonso no ceja en su empeño de establecer más y más relaciones entre la corteza cósmica y el meollo espiritual. No le importa que varios significantes se liguen por diversas razones a un mismo significado, ni que haya plurivalencia para un solo significante. Muchos son los que representan a Cristo: "Escriuano affigurauan a Mercurio los antigos quel aorauan [...] Et á ssemeiança de Ihesu Cristo, que ffue escriuano uerdadero, ca el su ssaber escriue todas las cosas"; "Fortaleza dauan los antigos a la planeta Mars, e poder de destruyr los enemigos. Et esto era a semeiança de Ihesu Cristo", fuerte en sufrir y vencedor del mundo y del diablo; "Honestad e derecho e uerdat dauan los antigos a Júpiter", pero "Júpiter es uerdadero Ihesu Cristo"; "Aries llamauan al primero ssigno, e este nonbre quier dezir tanto commo ffigura de carnero [...] Et esto ffue a ssemeiança de Nuestro Sseñor Ihesu Cristo, que ffue cordero de Dios Padre". También significan a Cristo, cada cual por sus propios motivos, Tauro, Cancro o "el Cangreio", "el León", Libra, "el Escurpión", Sagitario, Capricornio, Acuario y Piscis; Géminis alude a la unión hipostática; y todas estas correspondencias particulares no son obstáculo para que los doce signos del zodíaco representen corporativamente al colegio apostólico ${ }^{13}$. Además de la tierra, presagian a Santa Ma-

11 Ed. cit., pp. 84-86.

12 Ibid., pp. 76-80.

13 Ibid., pp. 82-83, 86-88, 91-113 y 115-116. 
ría la Luna y Virgo, símbolos de la castidad ${ }^{14}$. No podía hacerlo Venus, planeta-diosa a quien los gentiles habían atribuido influjo para "mouer ios cobdiçıosos amores et aduzırlos a conplido acabamiento de ssabor" 15; pero el Rey Sabio encuentra manera de incorporarla a la red de significaciones espirituales convirtiéndola en símbolo del amor más puro, la misericordia de Dios:

Amorosa dizíen los gentiles que era la terçera planeta, a que llaman Venus. $\mathrm{E}$ porque ha nonbre ffeminino, por esso le ffazian ffigura de duenna ffermosa. Et esto sse entiende por grant piadat de Dios que ouo contra nos [...] La ffigura quel dauan de donzella que teníe en la cabeça corona de violetas e tenia en la vna mano vn espejo e en la otra peynde, ésta es la piadat de Dios; que veyendo los que la han mester, acórrelos con ella e láualos e péynalos commo el peynde ffaze los cabellos, poniendo entre nos paz e amor. Et los pannos de color de violete que ssemeian ssanguino, que sse entiende por el ssu cuerpo, que ffué todo cubierto de ssangre por el martirio quel dieron ante quel pusiessen en la cruz e estando en ella después que tfué crucificado, et la corona quel pusieron en la cabeça de espinas, con que ge la ssangrentaron toda. Et por ende todas las vertudes e las amiztades que dieron a Uenus, a la piadat de Dios las deuyeran dar: ca en él yazen más que omne non puede asmar ${ }^{16}$.

Estudiando la General Estoria, María Rosa Lida de Malkiel ${ }^{17}$ y Francisco Rico ${ }^{18}$ han escrito páginas inigualables sobre la interpretación alegórica que permitió a la cristiandad medieval rescatar a su modo el mundo pagano. A los pasajes aifonsíes que ambos investigadores citan merecen agregarse con justicia la inesperada santificación de Venus y otro paralelo no menos sorprendente del Setenario también, el que se establece entre Tolomeo y San Juan Evangelista: aquél, el "omne que entendió e punnó en saber más las poridades de los çielos; éste, tan sabedor "de las poridades [de la Revelación] que ouo de ffazer libro que llaman Apocalipsi, que quier dezir en griego visiones marauillosas de los secretos de Dios" ${ }^{19}$. Dejemos la sorpresa, porque don Alfonso razona aquí con perfecta congruencia dentro de su plan, relacionando y contraponiendo al máximo conocer del significante -la física astral- y a quien con vista de águila penetró más hondo en el significado -el deslumbrante luminar de los arcanos divinos.

14 Ibid., pp. 81-82 y 100-101.

15 Ibid., p. 59.

16 Ibid., pp. 83-84.

17 "La General Estoria: notas literarias y filológicas", I, RPh, 12 (1958), I11-142; especialmente pp. 113-115 y 131-133.

1s Alfonso el Sabio y la "General Estoria", Barcelona, 1972, pp. 67-84.

10 Ed. cit., p. 113. 
De Dios, Alfa y Omega de la Creación, proceden los saberes y a El tornan la mirada: el trivium "muestra que Dios es Trinidat conplida" ${ }^{20}$; por medio de siete conceptos fundamentales de la geometría "sse muestran ssiete cosas que ha en Dios": "Derechurero es, commo linna derecha que non tuerçe a ninguna parte, e por essol llaman justo juez. Coruo es, ca esta ffigura muestra que sse abaxó con humillat [...] Cerco rredondo e egual es otrossí, ca El tiene ençerradas en ssí todas las cosas e ninguna non puede ende ssalir. Sobreffaz es, que cubre e mantiene todas las cosas [...] Longueza e ladeza ha muy grande [...] Cuerpo es otrossí spiritual, de que sson ffechos e fformados todos los otros" ${ }^{21}$. De igual manera las realidades y conceptos estudiados por la música, la "astrología", la "física" o medicina y la metafísica hallan correspondencia en cualidades, operaciones o facultades de la Divinidad ${ }^{22}$. Los saberes son moneda que lleva el nombre y señal de Dios; quien los desprecia, malbarata o envilece desprecia a Dios mismo ${ }^{23}$. El elogio del saber que don Alfonso hace en el Setenario se adelanta en un siglo al que había de hacer don Sem Tob, el gran panegirista de la inteligencia.

\section{NÚMERo y PALABRA, FUENTE DE SEMEJANZAS}

No pocas de las relaciones establecidas en el Setenario se basan en coincidencias numéricas o verbales; a veces, en unas y otras. La mentalidad medieval atribuía al número multitud de valores significativos. Recordemos las elucubraciones de Dante sobre el número nueve, correspondiente, según diversos calendarios, al día y mes en que Beatriz partió de este mundo; fundándose en que la raíz de nueve es tres, Dante infiere que su amada "era un nove, ciò è uno miracolo, la cui radice, ció è del miracolo, è solamente la mirabile Trinitade" ${ }^{24}$. Ya se ha dicho que las excelencias reconocidas por don Alfonso al número siete son el punto de partida para la organización a que sujetó su libro; ésta, a su vez, fomentó la busca de abundantes correspondencias. La comunidad de número sugirió la relación entre los siete cielos planetarios y los siete dones del Espíritu Santo ${ }^{25}$, las ya mencionadas del trivium con la Trinidad y de los doce signos del zodíaco con los doce apóstoles, etc., etc. Combinación de igualdad numérica y parentesco verbal se da en la ley XL, "De los artícolos de la Fe":

\footnotetext{
20 Ibid., p. 31.

21 Ibid., pp. 33-34.

22 Ibid., pp. 34-39.

23 Ibid., pp. 42-46.

24 Vita nova, § 29.

25 Ed. cit., pp. 80-81.
} 
Artículos quiere dezir tanto como artejos, e palabra es en latín [qu]e quiere dezir cosa que se tiene en vno, pero que se manda $e$ se mueue en dos maneras: la vna, cada artejo por sy; la otra, todos en vno. $\mathbf{E}$ esto se muestra en la mano e en el braço, en que ha siete partes que se mueuen: los çinco son los dedos [que se mueuen] por la mano; la sesta es la mano fasta el codo, e la setena es del cobdo fasta el onbro. [...] Muestran los artejos con la mano por la virtud de Dios; e el braço por la fuerça del [su] poder [...] Demás, quien bien [parare] mientes fallará en la mano catorze artejos que cada uno es más luengo que ella, pero cada vna mano e el braço e ellos fazen vna fuerça. E por ende la virtud del poder de los sacramentos, commo quier que sean departidos, vn poder e vna virtud han ${ }^{26}$.

La ecuación articulo $=$ artejo ha reclamado correspondientes espirituales para las extremidades corporales superiores. Las siete partes distinguidas en cada una de éstas se convierten en figura de los siete sacramentos, sin que por ello los catorce artejos dejen de simbolizar implícitamente los catorce artículos de la Fe, mencionados en el epígrafe de la ley y repartidos luego en siete relativos a la divinidad de Cristo y siete pertenecientes a su humanidad.

\section{DEFINICIONES Y ETIMOLOGías}

Si la naturaleza, la historia y los saberes están poblados de símbolos que el Rey Sabio escudriña con afán, es perfectamente explicable que se interesara con pasión por la etimología de las palabras, en el doble sentido de 'significación verídica' y 'procedencia' de ellas. En el Setenario abundan ya definiciones cuidadosamente acuñadas que pueden competir en maestría con las que pululan en las grandes obras historiales y jurídicas ${ }^{27}$. Repetidamente habla don Alfonso de nombres que fueron impuestos a las cosas, prueba de que para él la palabra no era vox naturalis, sino vox significativa ad placitum; pero, dentro de su convencionalidad, no era signo arbitrario, sino motivado. Para desentrañar su motivación el rey puso en juego los procedimientos usuales entonces, muy distintos en su teoría y en su técnica de los que hoy rigen la investigación etimológica: Hans-Josef Niederehe ha delineado sabiamente los tipos a que respondían aquéllos ${ }^{29}$. Con diferente perspectiva María

26 Ibid., pp. 70-71.

27 Véanse $\mathrm{H}$. A. VAN Scoy, "Alfonso $\mathrm{X}$ as a lexicographer", $H R, 8(1940)$, 277-284, y J. RoudrL, "Alphonse le Savant, rédacteur de définitions lexicographiques", Mélanges $P$. Fouché, Paris, 1970, pp. 153-175.

${ }_{28}$ Die Sprachauffassung Alfons des Weisen, Tübingen, 1975, pp. 169-179; para la relación entre palabra y cosa y para el carácter del signo en el ideario lingüístico alfonsí, pp. 32 y 54-56. 
Rosa Lida de Malkiel señaló con agudeza en las etimologías alfonsíes "otro aspecto del trascendentalismo, poco atento a la realidad histórica concreta e inclinado por eso a la alegoría [...] Alfonso (y su época), para quien la alegoría por excelencia es la que ve en el Antiguo Testamento la "figura" del Nuevo, encuentra natural que un vocablo hebreo o griego revele su verdadera significación dentro del latín" ${ }^{20}$. Habrá que ensanchar esta certera observación, ya que para Alfonso el Sabio la magna alegoría no se limitaba al Antiguo Testamento y la gentilidad, sino que comprendía el universo entero, tanto en el espacio como en el tiempo. Para él a los símbolos verbales les sucedía lo mismo que a los existentes en la naturaleza o en la historia: podían pasar inadvertidos hasta que alguien sorprendiera su sentido profundo. Una secuencia de fonemas ligada a un cierto significado en una lengua podía guardar oculto, como sentido simbólico en potencia, el significado que por designio divino había tenido o fuera a tener en otra lengua: entre los siete nombres de Dios que empiezan por $e$ y don Alfonso toma del hebreo el primero es $E l$, "que le cae muy derechamiente [. . ], ca atanto quiere dezir que él es en ssí mismo Dios en deidat" "20; la propiedad del nombre hebreo "El" no se descubre sino después de inyectarle la función deíctica del pronombre personal castellano "él", donde estaba escondido el sentido auténtico de la secuencia fonemática $/ e+1 /$. A veces el símbolo así descubierto no alcanza sólo al nombre, sino también a la cosa nombrada: el pan es imprescindible para la eucaristía por tres razones, "la primera por el nonbre dél, ca segunt palabra griega [ $\pi \tilde{\alpha} \nu]$, tanto quiere dezir en nuestro lenguaje commo 'todo'. Et por ende ffazen dello la hostia, que muestra que por ella rreçibimos cunplimiento de todo bien" ${ }^{31}$. El cristiano del siglo XIII, de igual modo que creía en la comunión de los santos, creía también en la comunión de las Ienguas, pues admitía la pasibilidad de transferir significaciones de unas a otras sin coexistencia ni tradición entre ellas, y aun de explicar así el nso de las casas designadas. Desde su punto de vista no eran tampoco frívolas ocnrrencias, sino hallazgos, la relación de Mars con amargo ${ }^{32}$, la de penitencia con pena y tener, ni que se defina conffessión como "palabra griega que quiere tanto dezir commo taiar el peccador los peccados que tiene ayuntados e enduresçidos en ssí" 33 ; tal definición presupone haber identificado 13-14.

29 "La General Estoria: notas literarias y filológicas", II, $R P h, 13$ (1956),

$$
\begin{aligned}
& 30 \text { Ed. cit., p. } 4 . \\
& 31 \text { Ibid., p. } 232 . \\
& 32 \text { Ibid.; p. } 88 . \\
& 33 \text { Ibid., pp. 182-183. }
\end{aligned}
$$


confessio y *confissio, potencial nombre de acción de confind e re 'hender, dividir, separar, abrir', aparte de entender esta acción como cosa propia de fisicos o médicos, lo que explica el supuesto grecismo.

\section{LÉXICO Y CAMPOS SEMÁNTICOS}

El interés léxico del Setenario no se reduce a sus definiciones y etimologías: en este libro primerizo se registra el vocabulario disponible en castellano para la exposición doctrinal al iniciarse la aventura intelectual y lingüística de las grandes empresas alfonsíes. El caudal léxico utilizable incluía ya multitud de cultismos, en su gran mayoría atestiguados antes (por ej., spiritu, justicia, misericordia, sacrificio, ydolo, ymagen; acucia, memoria, voluntad, ffantasia, opinion; officio, dignidat, ffama; fisica, natura, elementos, metal; philosopho, metafisica, materia, forma, causa, sustancia, entre muchos más ${ }^{34}$ ); pero no pocos tienen aquí su primera aparición conocida (libertad, mineral, "mar medioterránea", húmido, [letra] vocal, assumar 'sumar', centenario 'centena', quantidad, planeta. grado, punto, dieta, composiçion [farmacológica], los calcos natura naturador, natura naturada, en si, etc. $\left.{ }^{35}\right)$. No se habían incorporado aún al uso romance, pues se dan como latinos o griegos, requieren definición no se traducen con equivalentes castellanos, a $\mathrm{ng} \mathrm{u} \mathrm{lus}$ "rencón", a r t if e x "maestro conplido", a u r a "oriella", a u r ora, a uxili u m "ayuda", c lima, f e cundus "abastado", in te 11 ig e nçi a "entendimiento", intellectus [a gens] "entendimiento obrador", ty pus, "figura", etc. ${ }^{36}$ Aunque acidente y accidental, acidental constan en catecismos politico-morales algo anteriores, don Alfonso se cree en la necesidad de explicar acçidentes como "acaesçimientos de auentura que acaesçen después que la cosa es fecha"; a las pocas líneas emplea acaescimiento y evita acçidente. Sorprende la gran masa de voces que, pertenecientes al patrimonio oral, estaban ya habilitadas para la exposición culta e incluso para la nomenclatura científica (voz, letra, muchi-

34 Todos ellos y muchos otros del Setenario figuran en textos romances del Centro peninsular entre 1140 y 1252. Véase José Jesú's de Bustos Tovar, Contribución al estudio del cultismo léxico medicual, Madrid, 1974. (BRAE, anejo 28 ).

${ }_{35}$ Libertad, ed. cit, p. $8_{5} ;$ minerales, p. $28_{8} ;$ medioterránea, p. $20_{7} ; h \dot{u}$ mida, p. $51_{9}$; vocal, p. $4_{20}$; assumar, p. $31_{5}$; quantidad, p. $43_{22}$; planeta, p. $35_{2}$; grado, p. $35_{23}$; punto, p. $34_{8 \text { y } 18}$; p. $35_{23}$; dieta, p. $37_{12}$; composición, p. $37_{23}$; natura naturador y natura naturada, p. $27_{1 \text { y } 4}$; en ssi, p. $39_{8}$.

36 Angulus, artiffer aura, aurora, auxilium, ibid., pp. $3_{28}-4_{14}$; clima, p. $40_{9}$; ffecundus, p. $3_{9 \text { y } 15}$; intelligençia, intellectu $(\mathrm{s})$, pp. $38_{18 \text { y } 27}, 39_{3}$; tipus, p. $6_{1}$. 
guar, 'multiplicar', partir 'dividir', raiz [numérica], linna 'línea', cerco 'círculo', ssobreffaz 'superficie', cuento 'cálculo', 'número', etc.), así como la abundancia de derivados sobre base popular (longueza, ladeza o ancheza, establedat, entendimiento, sabiduria, ssintimiento, derechurero, sobejania 'exceso', etc. ${ }^{37}$ ).

Este léxico tan nutrido y jugoso aparece frecuentemente en el Setenario distribuido según campos semánticos, a veces con muy fina percepción de las oposiciones y diferencias significativas entre los términos de un mismo campo: así los relativos a la edad humana (ninnez, moçedat, mançebia, omne con sseso, veiedat y fallesçimiento 'decrepitud') ${ }^{38}$; a las unidades lingüísticas (boz, letra, sillaua, parte, dicho y rrazón ${ }^{39}$; a las operaciones matemáticas (contando, doblando, muchiguando, partiendo, ordenando, sacando la rraiz del cuento, assumando) ${ }^{40}$; a conceptos geométricos (linna derecha, corua, cerco, ssobreffaz, longueza, ancheza, cuerpo conplido $)^{41}$; a formas y fundamentos del' culto religioso (creençia o crençia, secta, opinión, autoiança, ffantasia, suenno, visión) ${ }^{42}$, etc. Rica mies, granada ya, para que el lexicólogo la coseche gozosamente.

\section{EL Setenario DENTRo DE LA OBRA ALFonsí}

El Setenario fue concebido por Fernando III y, según su mandato, compuesto por Alfonso $\mathrm{X}$ para que fuese guía de la propia conducta, dechado para sus sucesores en el trono y lección moral para sus súbditos. El móvil inicial fue el deseo de que "el entendimiento los aduxiesse a connosçer las cosas ssegunt que eran, primeramiente a Dios, dessí a ssí mismos, desí a todo lo ál que ouyesen a dezir o a ffazer" 43 . Los dos soberanos abrigaban el propósito y la esperanza de que sus gentes tuviesen "por fuero e ley conplida e cierta" 44 un conjunto de nociones que las orientara sobre la instalación del hombre en el cosmos y de reflexiones para que se apartaran de los males que cometían por "desentendimiento" o "des-

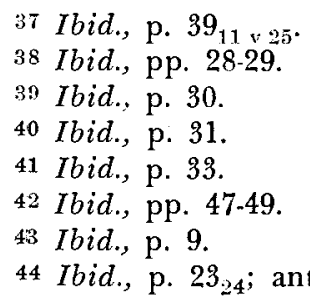
touyesen conseio de buen amigo"; después, líneas 24-25: "por que ouyesse a toller de los coraçones siete cosas en que errauan los que eran entonçe por desentendimiento"; p. 24, ${ }_{15}$ : "Et éstas desconnoçençias los ffazían desconnosçer a Dios". 
connoscencia". Don Alfonso puso la introducción que creyó más eficaz para esta finalidad ética: una visión teocéntrica del universo en la que todo cuanto habitaba el espacio o había acaecido en el tiempo aparecía como coro de ecos y suma de indicios de la Verdad suprema. Pasó después a exponer los dogmas capitales del cristianismo, así como las virtudes y práctica de los sacramentos, temas que exigían aleccionamiento más preceptivo. Comprendió entonces la necesidad de regular conductas mediante un planteamiento jurídico, no meramente religioso y moral; consecuentemente, parece haber dejado sin acabar el libro comenzado con gran amor y gran despliegue de la imaginación. Pero no lo desechó: no abandonó la técnica definitoria y etimológica empleadas en él, ni tampoco sus ideas rectoras. Lo tuvo presente en las Partidas: a la Primera se incorporaron pasajes del Setenario más o menos extensos y numerosos según las distintas redacciones de aquélla ${ }^{45}$; el carácter ético domina en amplias secciones de la Partida II. El simbolismo de la historia y la asunción de la antigüedad grecolatina, mediante la alegoría, al plan salvífico de Dios, son dos de los pilares en que descansa la General Estoria. Menos todavía abandonó el personalismo: si en el Setenario apuntan ya aspiraciones al Imperio ${ }^{46}$ y don Alfonso descubre que las siete letras de su nombre, providencialmente, empiezan con alfa y terminan con omega, "ssegunt el lenguaie de Espanna", a semejanza del nombre de Dios ${ }^{47}$, en la General Estoria se presentará como heredero de la serie de dinastías que inaugurada por Júpiter, había llegado hasta los sucesores de Federico Barbarroja ${ }^{48}$.

Madrid.

RAFAEl LAPEsa

45 Vanderford, introducción ed. cit., pp. xxviii-xl; J. A. ARias Bonet, "La Primera Partida y el problema de sus diferentes versiones a la luz del manuscrito del British Museum", en los estudios preliminares a su ed. de la Primera Partida, Universidad de Valladolid, 1975.

46 Setenario, ed. cit., p. 22.

47 Ibid.; p. 7.

48 FranCISCO RICO, op. cit., pp. 97-120. 